\title{
Foucault, Gilda e a Biopolítica: a eternidade de um conceito efêmero.
}

\author{
Foucault, Gilda and Biopolitics: the eternity of an ephemeral concept.
}

Arthur Arruda Leal Ferreira; Marcus Vinícius do Amaral Gama Santos

Universidade Federal do Rio de Janeiro

\section{RESUMO:}

Este artigo tem como objetivo chamar a atenção para a efemeridade do conceito de "Biopolítica" nos escritos de Foucault. Valendo-nos do procedimento detetivesco da historiadora Mary Henle, investigamos a emergência, a ascensão, as transformações, o declínio e o desaparecimento deste conceito, principalmente nos cursos Em Defesa da Sociedade (197576), Segurança, Território, População (1977-78) e Nascimento da Biopolítica (1978-79). Constatamos que, apesar de sua grande repercussão atual, tal conceito tem vida curta, tendo sua primeira aparição em 1974, sua primeira formulação mais elaborada em 1976 e seu desaparecimento parcial a partir de 1978 e quase total a partir de 1979. Entretanto, longe de desprezar tal conceito por sua curta duração cronológica, o comparamos com o personagem brasileiro Heleno de Freitas - apelidado Gilda - que deixou uma marca intensa na história, apesar de sua breve vida. A partir dessa comparação, concluímos tecendo considerações acerca do estatuto dos conceitos foucaultianos, atentando, principalmente, para seu caráter trágico, estratégico e bélico.

Palavras-chave: biopolítica; técnicas de segurança; personagens conceituais

\section{ABSTRACT:}

This article aims to draw attention to the ephemerality of the concept of "Biopolitics" in Foucault's writings. Using the detective procedure of the historian Mary Henle we investigated the emergence, the rise, the transformations, the decline and the disappearance of this concept, mainly in the courses In Defense of Society (1975-76), Security, Territory and Population (1977-78) and The Birth of Biopolitics (1978-79). We found that, despite its great current repercussions, such a concept had a brief life, having its first appearance in 1974, its first more elaborate formulation in 1976 and its partial disappearance in 1978 and almost complete disappearance in 1979. However, far from despising this concept for its short chronological duration, we compared it with the Brazilian character Heleno de Freitas - nicknamed Gilda who left an intense mark in history, despite his brief life. From this comparison, we conclude by making considerations about the status of Foucauldian concepts, paying particular attention to its tragic, strategic and bellic character.

Key-words: biopolitics; security techniques; conceptual characters

DOI:10.12957/mnemosine.2021.62172

\section{Introdução}

O conceito de biopolítica tem sua estreia em 1974 em terras brasileiras (FOUCAULT, 1981 [1974]), desponta no início de 1976 em duplo nascimento (FOUCAULT, 1988 [1976]; 2010 [1975-1976]) e praticamente desaparece no início de 1978 (FOUCAULT, 2006b [1977- 
1978]), tendo seu réquiem em 1979 (FOUCAULT, 1997 [1979]; 2007 [1978-1979]). Apesar da sua curta existência e dos rápidos trânsitos de sentido em sua breve passagem, este conceito se tornou crucial nas diversas leituras que fazemos hoje em dia do legado de Foucault. Este conceito se tornou chave em vários domínios, sendo utilizado ainda nos dias de hoje por vários autores na abordagem dos mais variados fenômenos: da existência das ciências humanas e médicas, passando pela medicalização e chegando nas pandemias recentes (para este último caso, cf. Tirado et alii, 2012; 2015). Mas, apesar da estrondosa repercussão, é um conceito de breve vida, trabalhado especialmente nos cursos proferidos no Collège de France. Consideramos que a presença do conceito em textos tardios (como conferências e entrevistas) só ocorre pelo fato dos mesmos terem sido publicados com estas datas tardias por conta do tempo de preparação para a publicação (envolvendo transcrição e tradução). Um exemplo é o artigo “As Malhas do Poder" (FOUCAULT, 1981 [1976]), publicado na década seguinte, a partir de uma conferência feita em 1976 em Salvador, Bahia. Igualmente, o conceito pode ter retornado em textos por pauta de entrevistadores, debatedores ou proponentes de conferências.

A proposta que fazemos aqui neste artigo é pensar a trajetória do conceito como um personagem em um enredo detetivesco-policial, tal como proposto pela historiadora da psicologia Mary Henle (1974) ao tomar o conceito de afecção (ou sentimento) na obra de Edward B. Titchener, examinando a trajetória deste termo ao longo dos escritos do psicólogo inglês e de seus colaboradores imediatos e deixando em suspenso as interpretações históricas mais canônicas. Considerando a trajetória curta, vibrante e com reviravoltas decisivas, muitos personagens de vida com grande intensidade e repercussão, mas com curta existência temporal, poderiam ser invocados: Cazuza, Cássia Eller, Janis Joplin, Jimi Hendrix, Jim Morrison e Kurt Cobain. No entanto, escolhemos comparar a trajetória deste conceito com um personagem brasileiro de trajetória intensa, curta e trágica como Heleno de Freitas, jogador de futebol que despontou no Botafogo do Rio de Janeiro nos anos de 1940. Também apelidado provocativamente de Gilda, personagem da atriz Rita Hayworth (de igual estrondoso sucesso e de curta passagem pelas telas de cinema), nosso personagem conheceu o mais alto glamour por meio do esporte e da alta sociedade carioca do seu tempo, cedendo a um período de escândalos e controvérsias que o conduzem, crise após crise, a sua internação no Manicômio de Barbacena, onde faleceu praticamente no anonimato. Colabora, para a particular escolha de Heleno de Freitas (ou Gilda), o percurso trágico do personagem, no qual loucura e mais alto glamour se entrecruzam em trama única e de grande intensidade ${ }^{1}$. Em suma, nossa proposta é tomar o método biográfico-detetivesco de Mary Henle para analisar o conceito de biopolítica, de seu 
início arrebatador, seus trânsitos, até seu silencioso desaparecimento, tomando sua trajetória como a de um personagem trágico, capaz de produzir uma eternidade em uma breve e intensa fulguração.

\section{Entre o detetivesco-biográfico e o genealógico}

Em 1974 , Mary Henle, historiadora da psicologia, publica o texto "E. B. Titchener and The Case of The Missing Element" [E. B. Titchener e o Caso do Elemento Perdido], reabrindo um dos casos mais enigmáticos relativos à psicologia experimental norte-americana do início do século XX: a reformulação empreendida por Edward B. Titchener - psicólogo experimental inglês e professor da Universidade de Cornell, em Nova York - em seu sistema, reduzindo o número dos elementos psicológicos básicos (sensações, sentimentos e idéias) a apenas dois, com a assimilação dos elementos sentimentais a elementos sensoriais (notadamente vinculados às sensações de pressão). A pertinência da reabertura deste caso, segundo a autora, se deu pelo fato de que ele fora arquivado, dado como resolvido, porém com justificativas bastante questionáveis em termos historiográficos. Em última instância, a autora busca rebater a versão estabelecida de forma incontestada até então por Edwin G. Boring ${ }^{2}$, clássico historiador da psicologia experimental e ex-aluno de Titchener. Para reabrir o caso deste "elemento perdido", Henle adota uma postura reconhecidamente detetivesca, se perguntando, tal como quando alguém é dado como desaparecido: "Quando esta pessoa foi vista pela última vez?" (HENLE, 1974: 143). A partir disso, a autora recua no tempo e nos acontecimentos, coletando novas evidências para solucionar o caso misterioso: coteja livros e artigos mais conhecidos, examina cartas, revê textos dos colaboradores imediatos de Titchener. Toda esta trajetória no reconhecimento da perenidade e mutação dos conceitos e na desconfiança das versões mais consagradas dos grandes comentadores.

É com postura semelhante que buscamos investigar o conceito de biopolítica nos ditos e escritos de Michel Foucault, i.e. como um "elemento perdido", apesar de sua estrondosa repercussão, que apaga a sua desaparição. Entretanto, nosso intuito não é, em última instância, determinar a causa ou o motivo para o seu desaparecimento, mas sim atentar para o seu caráter efêmero (como muitos outros conceitos inventados por Foucault) e expor: o momento e o modo de seu surgimento, as modificações pelas quais passou e seu desaparecimento em torno de dois anos. Empreitada que tem seu valor e sua importância pela grande repercussão que o conceito adquiriu nos últimos anos por meio das diversas apropriações críticas que sofreu. No momento em que algo é erigido como um grande conceito ou uma grande figura, não há nada mais 
coerente com os procedimentos de Foucault do que expor sua raridade histórica (FOUCAULT, 2007 [1978-1979], 1ª aula; VEYNE, 1978) ao mesmo tempo que levando em consideração a sua efetividade histórica.

Foucault, em seu prefácio à edição de 1972 de "A História da Loucura na Idade Clássica”, se recusando a assumir o lugar de dizer a verdade última sobre seu livro, diz que "gostaria que um livro [...] tivesse a desenvoltura de apresentar-se como discurso: simultaneamente batalha e arma, conjunturas e vestígios, encontro irregular e cena repetível" (FOUCAULT, 2019 [1972]: XXII). Portanto, à primeira vista, poderíamos tomar, da mesma forma, o conceito de biopolítica (e os textos nos quais ele foi desenvolvido) como discurso, entendendo que ele passou pelos mesmos processos que qualquer outro discurso: fragmentações, apropriações, batalhas e repetições. Entretanto, há de se levar em conta que Foucault - em sua aula inaugural no Collège de France, "A Ordem do Discurso" - expõe o "comentário" como um dos procedimentos internos de controle e de delimitação do discurso, entendendo que "o comentário limita o acaso do discurso pelo jogo de uma identidade que teria a forma da repetição e do mesmo" (FOUCAULT, 1996a [1970]: 29; itálicos no original). Levando isso em consideração, buscamos, por um lado, colocar a reflexão acerca dos rumos e percursos que o conceito de biopolítica tem tomado; e, por outro, apontar para o cuidado que deve se ter para não unificá-lo e para não reduzir os discursos foucaultianos à suposta permanência inalterada deste conceito. Contra esses procedimentos que buscam apaziguar os perigos dos discursos e dos conceitos, buscamos, portanto, retomar seu caráter de contingente, plural e efêmero, contrastando com o caráter de central, uno e englobante que tal conceito vem assumindo nos últimos anos. Não tomar esta grande repercussão como a garantia de sua necessidade, mas, ao contrário, entender, em sua trajetória fulgurante e variável, o brilho intenso de uma eternidade reverberada em efeitos mutantes de traduções e retraduções.

\section{Ascensão e declínio do império biopolítico}

Cada vez mais em certos campos, como na Psicologia, é quase imediata a associação de Foucault ao conceito de biopolítica. Ainda que a criação do neologismo não seja sua (de acordo com Esposito, 2011), é com ele que o conceito tem seu máximo reconhecimento. Teses, dissertações, monografias e uma enorme quantidade de artigos, coletâneas e livros de comentadores carregam esse conceito como marco central do trabalho de Foucault. Numa rápida consulta ao Google, ao acionarmos o item "Biopolítica", são disparadas cerca de mais de 641000 resultados $^{3}$. Igualmente importante são as apropriações pelas quais esse conceito 
passou com outros pensadores, como Gilles Deleuze (1992), Nikolas Rose (2011), Giorgio Agamben (2002), Peter Pelbart (2003), Achille Mbembe (2018), Byung-Chul-Han (2018) e Ricardo Esposito (2011): sociedade de controle, molecularidade, vida nua, biopotência, necropolítica, psicopolítica, bíos; todos esses conceitos têm alguma derivação da proposta de biopolítica. No entanto, o que tentaremos defender aqui é que esse conceito não tem, nos ditos e escritos do filósofo francês, a extensão que corresponde à sua repercussão. Como já vimos, a sua trajetória é curtíssima, tomando em especial atenção o que é trabalhado nos cursos do Collège de France. A primeira referência ao termo desponta no texto "O Nascimento da Medicina Social” (1982 [1974]), escrito a partir da conferência de mesmo nome proferida em 1974 na Universidade Estadual do Rio de Janeiro (UERJ) no Rio de Janeiro. Mas, o primeiro trabalho conceitual se dá somente no último capítulo de "A História da Sexualidade I: A Vontade de Saber" (FOUCAULT, 1988 [1976]) e na última aula do curso "Em defesa da Sociedade" (FOUCAULT, 2010 [1975-76]), obtendo o seu fim na quarta aula do curso "Segurança, Território e População" (FOUCAULT, 2006b [1977-1978]). Alguma sobrevida existe em artigos e entrevistas, um tanto pelo atraso das publicações e outro tanto pelos interesses de entrevistadores e dos públicos correspondentes. Assim, em 1981, por exemplo, é publicada, na revista "Barbárie" da Universidade Federal da Bahia (UFBA), um artigo, "As Malhas do Poder", em que o conceito é central. No entanto, isto se deveu ao tempo de transcrição e tradução da conferência do filósofo francês.

Que transformações podemos acompanhar no conceito se seguirmos os cursos "Em Defesa da Sociedade" (FOUCAULT, 2010 [1975-76]), "Segurança, Território e População (FOUCAULT, 2006b [1977-78]) e Nascimento da Biopolítica (FOUCAULT, 2007” [197879])? Veremos que, ao conceito, correspondem apenas quatro aulas: a última do primeiro curso e as três primeiras do segundo curso, dando uma vida de não mais que dois anos ao conceito, considerando ainda o intervalo de quase um ano e 10 meses entre esses dois cursos. Apesar desta curta vida, o conceito teve rápidas e variadas reformulações, semelhantes às que se deram com certos conceitos no período arqueológico, bem trabalhadas por Roberto Machado (1982). Igualmente, este rápido trânsito reforça o aspecto estratégico dos conceitos foucaultianos proposto por Márcio Goldman (2001), sempre em sintonia com as questões e lutas contemporâneas. Um dos aspectos mais interessantes é que a configuração do conceito mais conhecida atualmente só foi efetivamente trabalhada na última aula do curso "Em Defesa da Sociedade" (FOUCAULT, 2010 [1975-76]) e no último capítulo do primeiro volume de "A 
História da Sexualidade" (FOUCAULT, 1988 [1976]), de resto, dois textos de grande sobreposição de conteúdo.

No primeiro curso, o conceito é situado dentro de um poder específico, o biopoder, que se distingue do poder soberano. O biopoder se dividiria entre uma bio-política produtora de populações e uma anátomo-política constitutiva de indivíduos. A essa diferença de escala nas subdivisões do biopoder, corresponderia uma diferença de modo de funcionamento em relação à soberania. Se esta estaria calcada na lei, na interdição e no uso constante da morte como dispositivo exemplar (fazer morrer e deixar viver), o biopoder, estaria, por sua vez, embasado na norma e na constante observação ao longo do espaço e do tempo (de indivíduos ou populações), visando a intensificação e potencialização da vida (deixar morrer e fazer viver; FOUCAULT, 2010 [1975-76]: 202). Curiosamente, no fim do primeiro curso, um tema se destaca: o racismo de Estado enquanto uma configuração da biopolitica tomada pelo Estado na qual haveria uma supressão ou uma menorização de certas vidas em nome de uma vida ideal. Se, no livro A História da Sexualidade I: A Vontade de Saber (FOUCAULT, 1988 [1976]), o interesse era mostrar o dispositivo da sexualidade nas malhas entre a anátomo-política (ou disciplina) e a biopolitica, no curso Em Defesa da Sociedade (FOUCAULT, 2010 [1975-76]), o interesse é trabalhar, principalmente, o racismo de Estado.

Curiosamente, essa junção de anátomo-política e a biopolítica em torno do biopoder, cuja distinção opera no campo da escala e de modo de produção (entre indivíduos e populações), cede a uma distinção mais estratégica entre esses dois tipos de poder em Segurança, Território e População (FOUCAULT, 2006b [1977-78]: 21), onde a disciplina passa a se juntar mais à soberania em seus modos de regulação (seja pela proibição ou pela prescrição) em oposição ao biopoder e à biopolítica entendidos como técnicas de segurança (baseada na probabilidade, no cálculo de custos e na média ótima e aceitável). Mais do que uma distinção de escala e de modo de produção, agora temos uma distinção nas formas de regulação, em que, às denominadas “técnicas de segurança”, corresponderiam formas de intervenção variáveis, moldáveis estatisticamente, vinculadas ao meio e abertas aos acontecimentos. Muitos leitores confundem estas "técnicas de segurança" com um conceito que surge em curtíssimo tempo: governamentalidade. No entanto, mais do que uma simples identidade, entre os dois conceitos haveria um corte dado na aula de $1^{\circ}$ de Fevereiro de 1978, onde o filósofo francês restabelece a direção deste curso e do seguinte, curiosamente chamado de O Nascimento da Biopolítica ${ }^{4}$. No entanto, após esta aula de fevereiro, pouco se ouve falar em biopolítica ou biopoder. 
O que teria havido entre as duas formulações do conceito, e, especialmente, a aula de $1^{\circ}$ de fevereiro de 1978? Luciana Caliman (2002), em sua dissertação de mestrado no Instituto de Medicina Social (IMS) da Universidade do Estado do Rio de Janeiro (UERJ), destaca que houve uma grande mudança no conceito de poder. No entanto, mais do que uma mudança de conceito, entendemos que, especialmente no curso proferido entre 1978, há uma mudança de questão (referente aos modos de regulação e gestão das populações nos Estados) na qual o conceito de biopolitica parece não mais dar conta. Como esta questão teria surgido e reorientado a própria apresentação de conceitos? Passemos às alterações conceituais pelo exame do que é trabalhado em torno da biopolítica (e do biopoder) nos dois cursos.

\section{Em nome da guerra e em defesa da sociedade}

O curso Em Defesa da Sociedade (1975-76) teve por objetivo principal se perguntar quando foi possível pela primeira vez na história - e quem foi efetivamente o primeiro a enunciar - um discurso histórico-político, isto é, um discurso que entende a história como um desenrolar de enfrentamentos, combates, invasões, dominações, lutas e guerras, no qual a paz, a lei, as instituições políticas e a calmaria são apenas aspectos derivados momentâneos e nunca garantidos. Em suma, Foucault pergunta: “como, desde quando e por que se começou a perceber ou a imaginar que é a guerra que funciona sob e nas relações de poder?” (FOUCAULT, 2010 [1975-76]: 40); "Quem pensou primeiro que a política era a guerra continuada por outros meios?" (ibidem: 226). Para além desta questão que poderíamos nomear como "histórica", que diz respeito à emergência de um tipo específico de discurso, há também uma questão "metodológica" crucial, que diz respeito a grande parte das análises feitas por Foucault em seus cursos e livros anteriores: "a guerra pode valer efetivamente como análise das relações de poder e como matriz das técnicas de dominação?” (ibidem: 40); “o conjunto das noções derivadas da estratégia ou da tática podem constituir um instrumento válido e suficiente para analisar as relações de poder?" (ibidem: 226). Assim:

o essencial do curso será dedicado [...] ao problema da guerra. Eu gostaria de tentar ver em que medida o esquema binário da guerra, da luta, do enfrentamento das forças, pode ser efetivamente identificado como o fundamento da sociedade civil, a um só tempo o princípio e o motor do exercício do poder político. É mesmo exatamente da guerra que se deve falar para analisar o funcionamento do poder? São válidas as noções de 'tática', de 'estratégia', de 'relação de força'? Em que medida o são? O poder, pura e simplesmente, é uma guerra continuada por meios que não as armas ou as batalhas? (FOUCAULT, 2010 [1975-76]: 1819).

Articulando estas duas questões, podemos dizer que este curso de Foucault busca fazer uma genealogia da guerra como matriz de inteligibilidade do exercício do poder, mostrando sua 
emergência nos séculos XVI e XVII na Inglaterra e na França, e suas retranscrições nos séculos XVII e XVIII, que levaram à transformação da guerra exterior e binária em guerra interior e unitária na segunda metade do século XVIII e início do XIX. É justamente acompanhando essas transformações que o "esquema binário guerra" - assim como seus correlatos - se mostrará insuficiente para dar conta da modalidade de exercício de poder na Modernidade. Perda de primazia do esquema binário da guerra; advento da guerra biológica interna do biopoder.

Respondendo à questão histórica, Foucault aponta a emergência de um discurso efetivamente histórico-político nos discursos dos grupos populares ou pequeno-burgueses da Inglaterra do século XVI, sendo estes os Diggers e os Levellers. Entretanto, Foucault se deterá muito mais no caso francês, no qual um tal discurso surge apenas no século XVII com o nobre Henri de Boulainvilliers, que toma o discurso histórico da guerra, do espólio, da dominação constantes como instrumento político contra a crescente burocratização do reinado francês de Luís XIV e contra o procedimento pelo qual o poder real se auto-legitimava ao desenvolver narrativas que - suspendendo qualquer referência a enfretamentos concretos e efetivos na História - remetiam a origem do reinado e do estado de coisas ao Império Romano. Seria em Boulainvilliers que encontraríamos, efetivamente, narrativas históricas que não falariam mais de legitimação a partir de uma origem imperial romana, mas sim de dominações e conquistas que se dariam por meio de múltiplas lutas entre raças adversárias, nas quais umas invadiram e subjugaram outras, assim expandindo suas forças e seus domínios. É importante ressaltar que a noção de raça não possui, na época, o significado biológico que será atribuído a ela do século XIX em diante; em vez disso, ela era utilizada como sinônimo da noção, também muito específica, de nação ou sociedade: “A nação, ou melhor, 'as' nações, ou seja, os conjuntos, as sociedades, os agrupamentos de pessoas, de indivíduos que têm em comum um estatuto, costumes, usos, uma certa lei particular - mas lei entendida muito mais como regularidade estatutária do que como lei estatal" (FOUCAULT, 2010 [1975-76]: 112-113).

Não é sem motivo que Foucault faz questão de enfatizar que se deve falar em "as nações", no plural. Um ponto fundamental que caracteriza a guerra entre raças, entre nações ou entre sociedades é sua estrutura binária, segundo a qual "há dois grupos, duas categorias de indivíduos, dois exércitos em confronto" (FOUCAULT, 2010 [1975-76]: 43); "a guerra que solapa a nossa sociedade e a divide de um modo binário é, no fundo, a guerra das raças. [...] O corpo social é no fundo articulado a partir de duas raças" (ibidem: 51). Ou ainda:

há duas raças quando se faz a história de dois grupos que não têm a mesma origem local; dois grupos que não têm, pelo menos na origem, a mesma língua e em geral a mesma religião; dois grupos que só formaram uma unidade e um todo político à custa de guerras, de invasões, 
de conquistas, de batalhas, de vitórias e de derrotas, em suma, de violências; um vínculo que só se estabeleceu através da violência da guerra (FOUCAULT, 2010 [1975-76], p. 65).

Segundo esta concepção histórica, portanto, sempre há dois lados no campo de batalha: de um lado, o "nós" - isto é, a nossa raça, a nossa nação, a nossa sociedade - que abrange aqueles que lutam pelos nossos direitos, pela nossa vitória, pela nossa conquista; do outro lado, o "eles", os "não-nós" - que abrange os que não lutam por ou se opõem a nossos direitos, a nossas vitórias, a nossa conquista - são os que impedem o fortalecimento de nossa raça. Nesse sentido, dirá Foucault, "é sempre um discurso de perspectiva" (ibidem: 44), um discurso que fala a partir de um dos frontes de batalha, um discurso que possui, em si, a sede de conquista. E, dentro dessa guerra sem fim, não há síntese possível, mas apenas a disjunção exclusiva "dominar ou ser dominado", "vencer ou ser vencido": "os inimigos que estão à nossa frente continuam a ameaçar-nos, e não podemos chegar ao termo da guerra por algo como uma reconciliação ou uma pacificação, mas somente na medida em que formos efetivamente vencedores" (ibidem: 44).

O ponto fundamental neste discurso histórico-político para o qual chamamos a atenção - justamente por ser ele o que será essencialmente transformado com a emergência do biopoder - é, primeiramente, sua estrutura binária e, por consequência, seu caráter de essencial exterioridade. Isto é: se trata de uma guerra entre raças (estrutura binária) que, por definição, exige que sejam duas raças exteriores uma à outra, isto é: há sempre uma raça a qual nós pertencemos e que protegemos e uma raça a qual os outros pertencem enquanto inimigos, sem que haja qualquer intersecção possível entre estes conjuntos; ou se pertence à nossa raça e, portanto, deve-se ser protegido, ou se pertence à outra raça e deve-se ser dominado.

Partindo desse esquema geral das múltiplas guerras incessantes entre raças, Foucault trata, na segunda metade do curso, sobre duas retranscrições pelas quais a teoria da guerra das raças teria passado: a primeira, a retranscrição da luta de classes, que se deu por meio de alguns historiadores da época da Revolução Francesa; a segunda, a retranscrição biológica, que ocorreu no início do século XIX. A primeira retranscrição se deu por um apaziguamento parcial da guerra e, em última instância, por uma dialetização interna do discurso histórico: emerge uma dialética entre o gabarito da dominação - que emergiu com Boulainvilliers - e o novo gabarito da totalização - que emergiu com alguns historiadores da época da Revolução Francesa (Emmanuel-Joseph Sieyès, François Guizot, Augustin, Thierry e Conde de Montlosier), os mesmos que foram responsáveis pela dialetização dos dois gabaritos. Em última instância, essa restranscrição seria a da substituição da luta entre raças pela luta de classes e caracterizaria o 
advento de um discurso contra-histórico na medida em que introduz a concepção de totalização, sendo responsável pela relativização da predominância do gabarito de dominação.

Entretanto, a retranscrição que mais nos interessa aqui é a segunda, a retranscrição biológica - uma vez que ela acompanha a emergência do biopoder enquanto tal (em um salto cronológico de em torno de um século e de campo enfocado: dos discursos histórico-políticos aos modos de funcionamento do Estado). Essa retranscrição, segundo Foucault, se dá concomitante à primeira - isto é, na primeira metade do século XIX -, mas é responsável pela formação de um outro discurso contra-histórico, este caracterizado pela supressão da história em favor de uma perspectiva biológico-médica. É neste momento que ocorre a biologização da noção de raça que coincide com a emergência de um racismo biológico-social de Estado:

Retomando, reciclando a forma, o alvo e a própria função do discurso sobre a luta das raças, mas deturpando-os, esse racismo se caracterizará pelo fato de que o tema da guerra histórica - com suas batalhas, suas invasões, suas pilhagens, suas vitórias e suas derrotas - será substituído pelo tema biológico, pós-evolucionista, da luta pela vida. Não mais batalha no sentido guerreiro, mas luta no sentido biológico: diferenciação das espécies, seleção do mais forte, manutenção das raças mais bem adaptadas, etc. (FOUCAULT, 2010 [1975-76]: 68)

É também nessa retranscrição biológica que a noção de guerra das raças será profundamente transformada, agora perdendo suas características, até então essenciais, de binariedade e exterioridade. É como se, com tal retranscrição, houvesse uma interiorização da guerra: agora, os inimigos não mais sendo aqueles que pertencem a outra raça, a outra nação, a outro povo, mas sim interiores a nossa própria raça. Agora o critério separador entre nós e eles não coincide com a interioridade ou exterioridade em relação à raça em seu sentido históricopolítico que tivera até então; em vez disso, "nós" e "eles" pertencem a uma e mesma raça no sentido biológico e o critério de separação passa a ser a vida biológica por meio das normas estabelecidas pelas novas ciências médico-biológicas, dentre elas as que dizem respeito ao racismo biológico e à degenerescência:

a outra raça, no fundo, não é aquela que veio de outro lugar, não é aquela que, por uns tempos, triunfou e dominou, mas é aquela que, permanente e continuamente, se infiltra no corpo social, ou melhor, se recria permanentemente no tecido social e a partir dele. Em outras palavras, o que vemos como polaridade, como fratura binária na sociedade, não é o enfrentamento de duas raças exteriores uma à outra; é o desdobramento de uma única e mesma raça em uma super-raça e uma sub-raça.

[...] um combate que deve ser travado não entre duas raças, mas a partir de uma raça considerada como sendo a verdadeira e a única, aquela de detém o poder e aquela que é titular da norma, contra aqueles que estão fora dessa norma, contra aqueles que constituem outros tantos perigos para o patrimônio biológico. (FOUCAULT, 2010 [1975-76]: 52).

Ou ainda: 
o tema da sociedade binária, dividida entre duas raças, dois grupos estrangeiros, pela língua, pelo direito, etc. vai ser substituído pelo de uma sociedade que será, ao contrário, biologicamente monista. Ela será evidentemente ameaçada por certo número de elementos heterogêneos, mas que não the são essenciais, que não dividem o corpo social, o corpo vivo da sociedade, em duas partes, mas que são de certo modo acidentais. (FOUCAULT, 2010 [1975-76]: 68)

Apesar de discutir pontualmente temas relativos à retranscrição biológica em algumas aulas iniciais do curso Em Defesa da Sociedade (1975-76), é apenas na última aula deste curso - cujos elementos reaparecem em grande parte no último capítulo de seu livro do mesmo ano História da Sexualidade I: A Vontade de Saber (1988 [1976]) - que Foucault analisa propriamente a emergência e o funcionamento dos mecanismos do biopoder, focando principalmente no que diz respeito ao racismo de Estado. O biopoder é concebido como emergindo a partir de "um dos fenômenos fundamentais do século XIX [...] a assunção da vida pelo poder" (FOUCAULT, 2010 [1975-76]: 201; cf. FOUCAULT, 1988 [1976]: 133); e como constituído por dois pólos compatíveis de "poder sobre a vida" (FOUCAULT, 1988 [1976]: 131): a anátomo-política do corpo - cujo surgimento remonta às instituições disciplinares do século XVII - assegurada pelo exercido das disciplinas sobre o corpo-indivíduo; e a bio-política da população - cujo surgimento remonta à metade do século XVIII - assegurada pelo exercício de controles ou mecanismos reguladores sobre o corpo-espécie, diferenciando-se assim da soberania. No registro do biopoder, a norma passa a ter o papel fundamental de intercalar ambos os pólos: a norma se encontra tanto no âmbito das disciplinas, elegendo o que deve ser adotado e o que deve ser recusado para que cada um possa e queira viver melhor, quanto no âmbito dos mecanismos reguladores, identificando e possibilitando regular as curvas normais relativas aos fenômenos vitais da população (nascimentos, doenças, envelhecimentos, mortes, etc.). Assim, "a norma é o que pode tanto se aplicar a um corpo que se quer disciplinar quanto a uma população que se quer regulamentar" (FOUCAULT, 2010 [1975-76]: 213). E o ponto fulcral sobre o qual incidirão estas normas será a sexualidade, uma vez que há uma "posição privilegiada da sexualidade entre organismo e população, entre corpo e fenômenos globais" (ibidem: 212); disciplinando-se a sexualidade de cada indivíduo, regula-se os fenômenos de ordem populacional. Agora, a segurança da espécie (raça biológica) depende da vida sexual de cada um; os desviantes em relação às normas biológicas devem ser mortos em prol da pureza da raça biológica. É, precisamente, aqui, para a morte ativa dos impuros, que funcionará o racismo biológico.

Embora se trate de um “poder de 'fazer' viver e de 'deixar' morrer" (ibidem: 202), Foucault se questiona acerca do fato de que nunca antes na história do Ocidente houveram 
tantas guerras e tantas mortes desencadeadas ativamente: como um poder que se exerce pela vida - isto é, por meio da vida e tendo por fim a vida - pode ser responsável por tantas mortes? Se "a morte, como termo da vida, é evidentemente o termo, o limite, a extremidade do poder" (ibidem: 208), por que ela não foi suprimida por completo, em vez de apenas ter sido concentrada em um dado contingente populacional? A resposta para essas questões se encontra no racismo biológico, uma vez que este é o principal estabelecedor da divisão da raça biológica em puros e impuros; agora, com a biologização da noção de raça e com a supressão da relação guerreira em relação ao exterior, o racismo biológico será o meio de reestabelecer a divisão nós-eles, mas, desta vez, dentro de uma mesma raça. E, em última instância, o racismo biológico determina os que devem viver e os que devem morrer: "Com efeito, o que é o racismo? É, primeiro, o meio de introduzir afinal, nesse domínio da vida de que o poder se incumbiu, um corte: o corte entre o que deve viver e o que deve morrer. [...] Essa é a primeira função do racismo: fragmentar, fazer cesuras no interior desse contínuo biológico a que se dirige o biopoder" (ibidem: 214).

Mas o racismo biológico não apenas estabelece a divisão. Ele também convoca uma ação ativa de exterminação dos biologicamente mais fracos e debilitados, visando o aumento de força da raça biológica:

o racismo biológico vai permitir estabelecer, entre a minha vida e a morte do outro [...] uma relação do tipo biológico: 'quanto mais as espécies inferiores tenderem a desaparecer, quanto mais os indivíduos anormais forem eliminados, menos degenerados haverá em relação à espécie, mais eu - não enquanto indivíduo, mas enquanto espécie - viverei, mais forte eu serei, mais vigoroso serei, mais poderei proliferar'. [...] a morte do outro, a morte da raça ruim, da raça inferior (ou do degenerado, ou do anormal), é o que vai deixar a vida em geral mais sadia; mais sadia e mais pura (FOUCAULT, 2010 [1975-76]: 215).

Em última instância, o racismo biológico é o que não apenas possibilita, mas também torna necessário um certo âmbito de fazer morrer dentro do próprio funcionamento do biopoder: morte vital da sub-raça, do degenerado, do anormal; morte em prol da raça biológica e da soberania do Estado. Nesse sentido:

tirar a vida, o imperativo da morte, só é admissível, no sistema de biopoder, se tende [...] à eliminação do perigo biológico e ao fortalecimento, diretamente ligado a essa eliminação, da própria espécie ou da raça. A raça, o racismo, é a condição de aceitabilidade de tirar a vida numa sociedade de normalização (ibidem: 215 )

Portanto, nesse percurso, vemos o deslocamento de uma analítica do poder focada estritamente nas instituições disciplinares e que analisava a generalização das disciplinas em uma sociedade disciplinar - tal como ocorre no livro Vigiar e Punir (2014 [1975]) e em cursos como A Sociedade Punitiva (2015 [1972-1973]) e O Poder Psiquiátrico (2006a [1973-74]) - 
para uma analítica do poder focada no âmbito mais amplo da gestão da população por meio de mecanismos reguladores. Um ponto central deste percurso - e que será contrastado pelos cursos posteriores - é que o poder é exercido sempre no corpo e por meio do corpo: seja o corpo sequestrado e tornado dócil e útil pela disciplina, seja o corpo biológico e sexual, que, por um lado, é corpo humano individual disciplinado pela anatomo-política e, por outro lado, é corpoespécie ou corpo-população regulamentado pela bio-política. Como veremos a seguir, é justamente um deslocamento do corpo para a conduta que marca as análises posteriores de Foucault no que diz respeito ao biopoder, em novas composições de seus termos com a soberania.

\section{O canto de cisne da biopolítica: as técnicas de segurança}

Um ano e 10 meses depois, o curso seguinte (FOUCAULT, 2006b [1977-1978]: 15) se inicia lançando no mais alto protagonismo o conceito de biopoder: "Este ano, gostaria de começar o estudo de algo que, há tempo atrás chamei, um pouco no ar, de biopoder". Neste curso, esse protagonismo, que durará três aulas, possui três características fundamentais: 1) biopoder e biopolítica se encontram praticamente identificados (ibidem: 42), ao menos na referência ao suposto primeiro grande teórico delas (Jean-Baptiste Moheau); 2) esta aproximação se dá pois a junção da anátomo-política com a biopolítica na caracterização do biopoder é quebrada, apontando a singularidade dos modos de regulação da biopolítica no contraste com a soberania e a disciplina (aqui temos um novo quadro de parentesco na taxonomia das formas de poder); 3) esta singularidade aponta para as chamadas "técnicas de segurança”. É em torno destas últimas que estas três aulas são costuradas na definição de suas características (operação por meio das contingências, máxima atenção às variações do meio, abordagem em torno do funcionamento ótimo por meio do uso de médias e dispositivos estatísticos e consideração aguçada das multiplicidades e dos dos acontecimentos) e de alguns exemplos privilegiados (justiça, saúde e anormalidades, cidades, fome e grãos). Vejamos como são definidas essas técnicas de segurança de início, pensando em exemplos vinculados à justiça:

Dispositivo de segurança que, para dizer as coisas de maneira absolutamente global, vai inserir o fenômeno em questão, o roubo, dentro de uma série de acontecimentos prováveis. Segundo, as reações do poder frente a esse fenômeno se incorporarão a um cálculo, que é um cálculo de custos. E, terceiro, e último, ao invés de estabelecer uma divisão entre o permitido e o vedado, se fixarão por uma média considerada como ótima, e por outra, limites do aceitável, mais além dos quais já não poderá passar. Deste modo se esboça toda outra distribuição das coisas e mecanismos (FOUCAULT, 2006b [1977-78]: 21). 
A proposta inicial do curso então estava voltada para a definição destas técnicas de segurança acopladas a alguns temas especiais que conduziriam por fim à noção e à realidade da população como entidade:

Em primeiro lugar, gostaria de estudar um pouco, sobrevoar por assim dizer, o que poderíamos chamar de espaços de segurança. Segundo, estudar o problema do aleatório. Terceiro, estudar a forma de normalização que é específica da segurança, e que não me parece do mesmo tipo da normalização disciplinar. E, por último, chegar ao que vem a ser o problema preciso deste ano, a correlação entre a técnica de segurança e a população, como objeto e sujeito por sua vez destes mecanismos de segurança, vale dizer, o surgimento não só da noção, mas da realidade da população (FOUCAULT, 2006b [1977-78]: 27).

Como veremos mais adiante, este problema não alimentará todo o curso, mas sim as três primeiras aulas de forma intensa, destacando a singularidade do modo de funcionamento, regulação e normalização das técnicas de segurança (identificada à biopolítica) em contraste com a disciplina e a soberania. E, no protagonismo destas técnicas, o termo biopolítica vai desaparecendo ao longo das aulas na suposta identidade a estas (temos apenas as duas menções referidas no primeiro parágrafo desta seção). Deste projeto inicial, vemos que a análise das técnicas de segurança vai crescendo, por um lado, através dos exemplos: da justiça na primeira aula, passamos pelas enfermidades e normalizações na primeira e terceiras aulas (com as noções de caso, risco, perigo e crise; ibidem: 82), pelo espaço das cidades na primeira aula, pela fome e pela circulação dos grãos na segunda aula. Por outro lado, há um crescimento pela junção de atributos aos modos de operação das técnicas de segurança: do trabalho com a probabilidade, cálculo com custos e funcionamento em torno de uma média aceitável, são agregados o funcionamento com uma multiplicidade radical (primeira e segunda aula), a relação com o meio ambiente (boa parte da primeira aula), a irrupção da natureza (como elemento de realidade) na artificialidade da política (segunda aula), a liberdade (segunda aula) e a incorporação dos acontecimentos (todas as três aulas).

Ao longo desta expansão de exemplos e atributos, uma marca é constante: as técnicas de segurança são sempre contrastadas à disciplina e à soberania. Destacamos alguns trechos que explicitam o corte das técnicas de segurança especialmente com a disciplina, outrora irmanada com a biopolítica na definição do biopoder. Aqui são considerados alguns dos atributos já mencionados anteriormente:

A disciplina é essencialmente centrípeta. me refiro que ela funciona isolando um espaço, determinando um segmento. A disciplina, concentra, centra e encerra. Seu primeiro gesto, radica em circunscrever um espaço dentro do qual seu poder e os mecanismos deste atuarão de forma plena e sem limites [...] os dispositivos de segurança, tal como busquei apresentálos, tem uma tendência constante a ampliar-se: são centrífugos. Se integram sem cessar novos 
elementos [...] Se trata portanto de organizar, ou, em todo o caso, de permitir o desenvolvimento de circuitos cada vez maiores.

Em sequência, a segunda grande diferença: por definição, a disciplina regulamenta tudo. Não só não deixa fazer, mas que seu próprio princípio reza que nem sequer as coisas mais pequenas devem permanecer liberadas a si mesmas. A mais mínima infração à disciplina deve ser assinalada com extremo cuidado, justamente porque é pequena. $O$ dispositivo de segurança, pelo contrário, deixa fazer. Não deixa fazer tudo, claro, mas há um nível no qual a permissividade é indispensável [...] A função da segurança consiste em se apoiar nos detalhes [...] tomados por outro lado como processos necessários e inevitáveis, processo da natureza no sentido lato; e se apoiará neles [...] para obter algo que em si se julgará pertinente por situar-se no nível da população [...]

Também o mecanismo disciplinar codifica em forma permanente o permitido e o proibido, ou melhor dito, o obrigatório e o proibido; o ponto ao que se aplica o mecanismo disciplinar, então, não é tanto que não deve fazer-se, como o que deve fazer-se [...]. O dispositivo de segurança, tal como acabo de expô-lo me parece que se trata justamente de não adotarem o ponto de vista que que se impede nem o ponto de vista do que é obrigatório, e tomar em troca a distância suficiente para captar o ponto onde as coisas vão se produzir, sejam desejáveis ou indesejáveis (FOUCAULT, 2006b [1977-78]: 66-68).

Em poucas palavras, é esse elemento de realidade e seus modos de regulamentação que marca as técnicas de segurança. Isso é pensado especialmente quanto à circulação de grãos, como o trigo:

Em outras palavras, a lei proíbe, a disciplina prescreve e a segurança, sem proibir nem prescrever [...] tem a função essencial de responder a uma realidade de tal maneira que a resposta a anule: a anule, a limite, a freie ou a regule. Esta regulação no elemento da realidade é, creio, o fundamental nos dispositivos de segurança (FOUCAULT, 2006b [197778]: 69).

Assim, as técnicas de segurança se destacam das formas geradas pela soberania e disciplina pela singularidade de seu funcionamento na produção da população como discurso e realidade. Isso não implica, por outro lado, em uma espécie de evolução cronológica e substitutiva das formas de poder; estas coabitariam os mais diversos dispositivos: “ Não há era do legal, era do disciplinar, era da segurança” (FOUCAULT, 2006b [1977-78]: 23). O que temos, em última instância, é uma história das técnicas e das práticas (e não das ideologias) traçadas em dispositivos complexos:

De fato, há uma série de edifícios complexos nos quais a mudança afetará, desde logo, as técnicas mesmas que vão aperfeiçoar-se ou em todo caso, a complicar-se, mas o que vai mudar é sobretudo a dominante, ou mais exatamente o sistema de correlação entre os dispositivos mecanismos jurídico-legais, os mecanismos disciplinares e os mecanismos de segurança. Em outras palavras, veremos uma história que vai ser a história das técnicas propriamente ditas (FOUCAULT, 2006b [1977-78]: 23).

Contudo, a quarta aula deste curso (a de $1^{\circ}$ de Fevereiro de 1978) configura um corte no desenvolvimento temático do mesmo: ainda que os dispositivos de segurança sejam referidos 
neste encontro, vai haver uma mudança de questão, reordenadora de todo o curso e do seguinte: a entrada do problema do governo numa nova série segurança-população-governo (FOUCAULT, 2006b [1977-78]: 110), especialmente voltado para o tema do Estado, "a forma particular de governo que vai se aplicar ao Estado" (FOUCAULT, 2006b [1977-78]: 118). A pergunta, sem escapar de uma análise microfísica do poder, é: como o Estado se governamentaliza, ou seja, se volta para a população? Nas palavras do filósofo francês:

No fundo, se tivesse querido dar ao curso proposto este ano um título mais exato, com segurança não havia escolhido "Segurança, território e população". O que queria fazer agora, se tivesse verdadeiro interesse em fazê-lo é algo que chamaria uma história da 'governamentalidade' (FOUCAULT, 2006b [1977-78]: 135-136).

E será exatamente isso que Foucault fará, representando uma total guinada na sequência do curso: saem as técnicas de segurança ${ }^{5}$, o biopoder e a biopolítica (pouco referidos no resto deste e no próximo curso) e entra a governamentalidade como conceito central, outras condições de possibilidade (o poder pastoral), outras formas de manifestação (O Estado de Polícia e a Razão de Estado, por uma lado, e as formas Liberais e Neoliberais de governo, por outro lado) e, mesmo, uma nova definição de poder em um modelo não mais bélico-guerreiro (CALIMAN, 2002). Vejamos estes aspectos em linhas gerais. O conceito central aqui trabalhado é o de governamentalidade entendido como uma arte, ou "a maneira meditada de fazer o melhor governo e também ... sobre a melhor forma possível de governar" (FOUCAULT, 2007 [1978-1979]: 17). Posteriormente, o conceito ganha formulações mais simplificadas como "maneira de condução da conduta dos homens" (ibidem: 208), independente do alcance (seja o governo das almas do cristianismo primitivo ou as modernas estratégias de governo liberal) e de sua exequibilidade (seu sucesso ou fracasso). Seriam formas de gestão da vida de todos e de cada um conforme a fórmula: “Omnes et singulatim” (FOUCAULT, 1996b [1979]).

Para fazermos uma breve genealogia dessas formas com que o Estado se governamentaliza, destacaríamos o que Foucault entende como condição de possibilidade das formas modernas de governo das populações: o poder pastoral, demarcado em práticas de gestão presentes no Antigo Testamento e no Cristianismo Primitivo (da quinta à nona aula de Segurança, Território e População). Este poder seria demarcado pelas seguintes características: 1) o pastor exerce o poder sobre um rebanho e não sobre uma terra; 2) o pastor reúne, guia e conduz o seu rebanho (basta que o pastor desapareça para que o seu rebanho se disperse); 3) o papel do pastor é garantir a salvação de seu rebanho, cuidando de cada indivíduo dia após dia; 4) a relação do pastor para com o seu rebanho é de devotamento; tudo o que ele faz está voltado para o bem de seu grupo (FOUCAULT, 1996b [1979]: 80-81). Esse dispositivo pastor-rebanho 
seria condição crucial nas formas de governo dos Estados Modernos, dado seu aspecto simultaneamente coletivizante e individualizante, ausentes de outras definições de poder, como as presentes na Grécia clássica, em que o rei dificilmente seria identificado a um pastor, responsável pelo cuidado de uma população. Para tal diferenciação, Foucault, (2006b, [19771978]: 161-179) toma como exemplo a análise de Platão, feita pelo método de divisão no diálogo "O Político".

Pensando na genealogia dessas formas de governo, Foucault (2006b [1977-1978]), da décima à décima-terceira aula, trabalha as formas com que a governamentalidade se implementa como forma estatal no Ocidente, especialmente a partir do século XVI. Para tal, há a junção de três figuras: o equilíbrio diplomático entre nações, a polícia e a razão de Estado. Desse modo, a governamentalidade moderna se implementaria no conjunto partilhado entre: uma Razão de Estado, que buscava determinar as necessidades essenciais deste enquanto entidade singular; o ajuste diplomático das forças entre os Estados; e a Polícia, enquanto conjunto de objetivos, objetos e instrumentos internos do Estado a fim de controlar homens e riquezas. Esta Racionalidade Governamental surge através de uma série de manuais como os de Guillaume de La Perrièrre e outros autores menos conhecidos (Huhental, Bottero, Palazzo e outros), em que são propostos objetos de atuação, objetivos e estratégias delimitadas. O alvo de atuação do Estado é a gestão de riquezas e homens em diferentes níveis de governo, que se implicam mutuamente, seja o de si (moral), o da família (economia) ou o do Estado (política).

Contudo, esta racionalidade não se coloca de modo puro no interior das práticas de governo na época. A razão de governo, expressa inicialmente no mercantilismo e no cameralismo, se encontra entrelaçada com a soberania. O que desbloqueia, desenlaça e libera essa nova governamentalidade é a explosão demográfica da população do século XVII na Europa. Com isso, a família deixa de ser modelo de governo e torna-se instrumento de intervenção; a população transforma-se em alvo e instrumento para o governo; e a economia, de governo das famílias, torna-se um modo racional de intervenção e controle ou um nível singular de realidade, uma vez que a soberania se veja superada (FOUCAULT, 2006b, [19771978], aula de $1^{\circ}$ de fevereiro de 1978).

Na sequência dessa história, essas formas governamentais do Estado de Polícia são postas em questão através dos fisiocratas, especialmente a partir do século XVIII. Estes modos de gestão são problematizados em nome do mercado (FOUCAULT, 2006b, [1977-1978]) ou ainda da sociedade civil (FOUCAULT, 2007, [1978-1979]). Ao longo do tempo, esse processo é invertido: o mercado, a partir do século $\mathrm{XX}$, não seria apenas um instrumento crítico do 
governo, mas transforma-se na própria racionalidade deste, que regularia outros domínios, como a família, a natalidade, a delinqüência e a política penal (FOUCAULT, 1997: 96). Inaugura-se aqui um modo de governo liberal, embasado no acompanhamento do movimento das populações enquanto processos naturais. Essa naturalidade, portanto, seria acessível à ação concreta do governo, um governo que produz efeitos benéficos através do desejo coletivo e a partir da possibilidade do desenvolvimento de saberes sobre a população. Este tema é desenvolvido na última aula de Segurança, Território, População (FOUCAULT, 2006b, [19771978]) e em parte do curso seguinte, Nascimento da Biopolítica (FOUCAULT, 2007, [19781979]), centrado nas formas neo-liberais presentes no ordo-liberalismo alemão e na Escola de Chicago.

É nos marcos de um liberalismo que a ciência econômica passaria a ter um papel preponderante. Mas, além da economia, saberes como a higiene pública e a medicina social também trazem a questão da população e do saber sobre ela como técnica indispensável ao bom governo. Em todos os casos, o conhecimento científico torna-se condição para uma racionalidade governamental que atuaria sobre os processos supostamente naturais. Esta atuação já não se trata de uma regulamentação: a intervenção estatal artificial pode tornar-se até prejudicial na medida em que a natureza dos processos sociais se regularia por si mesma. Assim, a liberdade não é tomada mais como simples direito dos indivíduos, mas como condição para se governar. A liberdade, aqui, não é tanto conceito, mas técnica de governo ${ }^{6}$. Essa ênfase nas formas de natureza e liberdade se alteram diante das formulações das escolas neoliberais do século XX, onde prepondera a criação das condições artificiais de competição, especialmente no ordo-liberalismo, tema do curso seguinte, "O Nascimento da Biopolítica" (FOUCAULT, 2007 [1978-79]).

\section{Réquiem ou nascimento da Biopolítica}

Dando sequência à exposição do curso seguinte, apresentado em 1978-1979, vale destacar que o termo Biopolítica aparece basicamente no título e em breves passagens deste (FOUCAULT, 2007 [1978-79]), e mesmo no resumo do curso (FOUCAULT, 1997 [1979]). Uma consulta ao índice onomástico do curso aponta não mais que cinco referências ao termo; estas breves manifestações podem ser entendidas mais como uma espécie de réquiem do conceito. Uma breve passagem no corpo do curso é emblemática da abordagem coadjuvante do conceito neste curso: "Lhes asseguro que, apesar de tudo, em um começo, tive, na verdade a intenção de falar-lhes de biopolítica, mas depois, como as coisas são o que são, resulta que 
terminei por falar-lhes extensamente - demasiado extensamente talvez - do neo-liberalismo..." (ibid., p. 217). De forma mais explícita, em “O Nascimento da Biopolítica”,neste curso o que se busca são formas mais contemporâneas de condução da conduta, onde figuras como a empresa e o capital humano se oferecem como formas de avaliação e compreensão dos mais diversos fenômenos coletivos, como a organização familiar ou o controle das drogas, trabalhados agora a partir de condições artificiais de produção (e não mais fluxos naturais, como as postuladas na fisiocracia). Diferente das técnicas de segurança, tais fenômenos não são mais avaliados por aspectos como norma, acaso, média, relação com o ambiente, mas na relação com vetores como custo, riscos, investimento e benefícios. Aqui a biopolítica se torna claramente um assunto genericamente populacional.

Neste aspecto, é importante o percurso que leva à conclusão deste curso de 1978-1979: após analisar o ordoliberalismo alemão e o anarcoliberalismo alemão, Foucault retorna nas duas aulas finais para se indagar sobre as condições de possibilidade do homo economicus (próprio das artes de governar liberais), vinculado às formulações no início do século XIX do conceito de sociedade civil, como nas análises de Adam Ferguson. Nos momentos finais do curso, Foucault entende que se instalou uma múltipla racionalidade governamental entre o homo juridicus e o homo economicus, que "se encavalam, se apoiam, se rebatem, se combatem umas às outras (ibidem: 358): “Arte de governar na verdade, arte de governar na racionalidade do Estado soberano, arte de governar na racionalidade dos agentes econômicos, e, de uma maneira geral, arte de governar na racionalidade dos mesmos governados" (ibidem: 358). E é justamente na sobreposição das artes de governar que surgiria o debate político do século XIX: “O que é a política, por fim, se não o jogo dessas diferentes arte de governar com seus diferentes ajustes, e, por sua vez o debate que elas suscitam" (ibidem: 358). No final do curso, vemos o nascimento da política, mas não o da biopolítica.

Este réquiem tem sua marca final no resumo do curso, publicado seis meses depois do fecho do curso. Logo na abertura, é feita uma referência à Biopolítica, uma vez que estaria conectada ao tema da população, objeto das formas governamentais liberais: "O tema escolhido foi, portanto, a 'biopolítica': entendia por 'biopolítica' a maneira pela qual se tentou desde o século XVIII racionalizar os problemas propostos à prática governamental, pelos fenômenos próprios a um conjunto de seres vivos constituídos em população: saúde, higiene, natalidade, raças..."(FOUCAULT, 1997: 89). A Biopolítica se torna um assunto de racionalidade governamental de populações. 
Por fim, essa transformação das questões conduzidas nestes dois cursos, de 1977-1978 e de 1978-1979, assim como de sua grade conceitual e de sua narrativa histórica, é completada por uma transformação na própria analítica do poder: da sua concepção inicial como relação agonística entre corpos (distante de qualquer concepção econômica ou jurídica) e onde a resistência se daria nas reversões das próprias relações de força, temos agora uma nova proposição a partir destes trabalhos sobre governamentalidade. É desta forma que o poder passa a ser entendido como ações sobre ações (conduções de condutas, onde a liberdade é uma condição e a violência e a coerção estão excluídos; FOUCAULT, 1995 [1982]). Um bom guia para estas transformações é a dissertação de Luciana Caliman (2002): "Dominando corpos, conduzindo ações: Genealogias do Biopoder em Foucault”.

\section{Conclusão}

Após esta investigação sobre o conceito de biopolítica, podemos tecer alguns comentários sobre seu surgimento intenso e seu desaparecimento em tão curto tempo. $\mathrm{Na}$ adesão ao método policial-detetivesco de Henle (1974) na história das ciências, tratamos da ascensão meteórica e da desaparição praticamente total do conceito de biopolítica em uma espécie de morte abrupta (diferente do conceito de sentimento em Titchener que possui uma desaparição gradual). A suposição em nosso laudo de perícia é que o conceito é abandonado pelas suas reconexões e filiação a novas questões. Conforme Goldman (2001), é neste aspecto estratégico e no calor das batalhas que devemos entender a produção dos conceitos foucaultianos. É desta forma que o termo biopolítica pôde se conectar com as questões referentes ao racismo de Estado ou ainda ao dispositivo de sexualidade, mas cede ao de governamentalidade no entendimento de como o Estado se governamentaliza ou quando as populações se tornam objeto de um tipo especial de gestão. A reformatação que o conceito passa a ter nas três primeiras aulas de Segurança, Território e População, lipoaspirado da disciplina e possuidor de novos atributos (sensibilidade ao acaso, ao acontecimento e às variações do meio, além de lastreamento nas forças da natureza e na liberdade, e intermediado pela avaliação em torno de valores médios) não dá conta do que a nova questão demanda, seguramente tendo em vista a problematização da governamentalidade liberal. E neste aspecto o desapego estratégico de Foucault a seus conceitos é única: na variação das lutas, novos armamentos conceituais são produzidos.

A configuração desta ascensão meteórica, seguida de desaparição súbita, com enormes efeitos posteriores, torna este conceito semelhante a uma celebridade de vida curta e intensa 
que ocupa consistentemente nossa memória, recusando-se à dissipação. Assim operou o conceito de biopolítica: este desaparece no pico de sua glória, distribuindo sua herança diferenciada entre vários pensadores, comentadores e leitores de Foucault. Dos vários personagens que despontam neste paralelo, Heleno de Freitas talvez tenha sido o mais interessante: diferente dos demais, não houve a conjugação de uma morte trágica com o auge do reconhecimento. Há sim uma lenta desaparição, ou o que poderíamos chamar de uma dupla morte no sucumbimento à loucura, e sua passagem por longos anos no Manicômio de Barbacena. O mais brilhante e glamouroso de uma bela existência no flerte direto com a experiência trágica da loucura, na desmedida da própria vida.

Talvez os conceitos propostos por Foucault operem nesta mesma deriva trágica: o seu ápice e sua mais intensa cintilação já são o sinal de seu iminente desaparecimento. Fora das linhas de guerra e batalha, eles podem se tornar ornamentos desnecessários. Não lhes cabe a paz dos sistemas de pensamento geometrizados. Assim como a vida trágica das celebridades não caberia no molde das "almas bem pequenas/ Remoendo pequenos problemas" (Cazuza, 1989), ou "no trono de um apartamento/ Com a boca escancarada, cheia de dentes/ Esperando a morte chegar" (Seixas, 1973). O desassossego trágico diante da promessa de qualquer paz perpétua e diante do que se apresenta naturalizado e cristalizado no presente impulsa conceitos e existências no brilho eterno de uma breve existência. No limiar da batalha, da loucura e de um brilho maior da vida.

\section{Referências}

AGAMBEN, Giorgio. Homo Sacer. Belo Horizonte: Editora UFMG, 2002. [Trabalho originalmente publicado em 1995].

BORING, Edward Garrigues. A History of Experimental Psychology. Nova York: Appleton Century - Crofts, 1929.

CALIMAN, Luciana. Dominando corpos, conduzindo ações. Genealogias do Biopoder em Foucault. Dissertação (Mestrado em Saúde Coletiva) UERJ, Rio de Janeiro, 2002.

CAZUZA. Blues da Piedade. In: CAZUZA. Ideologia. Rio de Janeiro: Philips, 1989.

DELEUZE, Gilles. Post-scriptum sobre as sociedades de controle. In: DELEUZE, Gilles. Conversações. São Paulo: Editora 34, 1992.

ESPOSITO, Roberto. Bíos: Biopolítica e filosofia. Buenos Aires/ Madri: Amorrortu, 2011.

FOUCAULT, Michel. O nascimento da medicina social. In: MACHADO, Roberto. (Org.). Microfísica de Poder. Rio de Janeiro: Graal, 1982. [Conferência pronunciada em 1974].

FOUCAULT, Michel. As malhas do poder. In: Barbárie no 4/5, 1981/1982. [Conferências pronunciadas em 1976]. 
FOUCAULT, Michel. História da Sexualidade I. A vontade de Saber. Rio de Janeiro: Graal, 1988. [Livro originalmente publicado em 1976].

FOUCAULT, Michel. Préface, in Foucault, (M.), Folie et Déraison. Histoire de la folie à l'agê classique. In: DEFERT, Daniel. e EWALD, François. (Orgs.). Dits et Ecrits. Paris: Gallimard, 1994 [Prefácio retirado em 1972, mas escrito junto com o corpo da tese em 1961].

FOUCAULT, Michel. O Sujeito e o Poder. Em: DREYFUS, Hubert. \& RABINOW, Paul. (Orgs.). Michel Foucault na trajetória filosófica. Rio de Janeiro: Forense Universitária, 1995. [Artigo publicado em 1982].

FOUCAULT, Michel. A ordem do discurso. São Paulo: Loyola, 1996a. [Aula inaugural no Collége de France pronunciada em 1970].

FOUCAULT, Michel. Omnes et singulatim. Em: MOREY, Miguel. (Org.). Tecnologias del yo. Barcelona: Paidós/ICE - UAB, 1996b. [Curso original de 1979]

FOUCAULT, Michel. 1978 - 1979: Nascimento da biopolítica. In: FOUCAULT, Michel. Resumo dos cursos. Rio de Janeiro: Zahar, 1997. [Resumo publicado originalmente em 1979].

FOUCAULT, Michel. O poder psiquiátrico: curso no Collège de France (1973-1974). Trad. Eduardo Brandão. São Paulo: Martins Fontes, 2006a. [Curso ministrado originalmente de novembro de 1973 a fevereiro de 1974].

FOUCAULT, Michel. Seguridad, Territorio y Población. Buenos Aires: Fondo de Cultura Económica, 2006b. [Curso original de 1977-1978].

FOUCAULT, Michel. Nacimiento de la biopolítica. Buenos Aires: Fondo de Cultura Económica, 2007. [Curso original de 1978-1979].

FOUCAULT, Michel. Em defesa da sociedade: curso no Collège de France (1975-1976). São Paulo: Editora WMF Martins Fontes, 2010. [Curso ministrado originalmente de janeiro a março de 1976].

FOUCAULT, Michel. Vigiar e punir: nascimento da prisão. Trad. Raquel Ramalhete. 42. ed. Petrópolis, RJ: Vozes, 2014. [Livro publicado originalmente em 1975].

FOUCAULT, Michel. A sociedade punitiva: curso no Collège de France (1972-1973). Trad. Ivone Benedetti. São Paulo: Editora WMF Martins Fontes, 2015. [Curso ministrado originalmente de janeiro a março de 1973].

FOUCAULT, Michel. A História da Loucura. São Paulo: Perspectiva, 2019. [Livro originalmente publicado em 1961].

GOLDMAN, Marcio. Objetivação e Subjetivação no último Foucault. Em: CASTELO BRANCO, G. \& NEVES, L. F. B. (Orgs.). Michel Foucault: da arqueologia do saber à estética da existência. Rio de Janeiro \& Londrina: Nau \& CEFIL, 1998.

HAN, Byung-Chul. Psicopolítica: O neoliberalismo e as novas técnicas de poder. Tradução de Maurício Liesen. Belo Horizonte: Editora Âyiné, 2018.

HENLE, Mary. E. B. Titchener and the case of the missing element. Journal of the History of the Behavioral Sciences, v. 10, n. 2, 1974, p. 227-237.

MBEMBE, Achille. Necropolítica. São Paulo: n-1, 2018. 
MACHADO, Roberto. Ciência e Saber: a trajetória arqueológica de Michel Foucault. Rio de Janeiro: Graal, 1982.

NIETZSCHE, Friedrich. O Nascimento do trágico. São Paulo: Companhia da Letras, 2001.

PÉLBART, Peter Pál. Vida Capital. São Paulo: Iluminuras, 2003.

RODRIGUES, Heliana de Barros Conde. Ensaios sobre Michel Foucault no Brasil. Rio de Janeiro: Lamparina, 2016.

ROSE, Nikolas. The politics of life itself: biomedicine, power, and subjectivity in the twentyfirst century. Princeton: PUP, 2007.

SEIXAS, Raul. Ouro de tolo In: SEIXAS, R. Krig'ha Bandolo. Rio de Janeiro: Phillips, 1973.

TIRADO, Francisco; GÁlVEZ, Ana; CASTILlO, Jorge. Movimiento y regímenes de vitalidad. La nueva organización de la vida en la biomedicina. Política y Sociedad, vol. 49, n 3, p. 571-590, 2012.

TIRADO, Francisco; GÓMEZ, Andrés; ROCAMORA, Verónica. The global condition of epidemics: Panoramas in A (H1N1) influenza and their consequences for One World One Health program. Social Science \& Medicine, vol. 129, p. 113-122, 2015.

VEYNE, Paul. Foucault revoluciona a história. In: VEYNE, Paul. Como se escreve a história? Brasília: Universidade de Brasília, 1980.

Arthur Arruda Leal Ferreira

Doutor em Psicologia (Psicologia Clínica) pela Pontifícia Universidade Católica de São Paulo (1999). Realizou Pós-Doutorado na UNED (Madrid) em 2010 sobre História da Psicologia e na Universidad Janveriana (Bogotá) em 2014 sobre Produção de Subjetividade, sendo apoiado pela CAPES nos dois pós-doutorados. Professor Titular da UFRJ.

E-mail: arleal1965@gmail.com Orcid: https://orcid.org/0000-0002-2059-8877

Marcus Vinícius do Amaral Gama Santos Mestrando pelo Programa de Pós-Graduação em Psicossociologia de Comunidades e Ecologia Social (PPGP-EICOS) do Instituto de Psicologia da Universidade Federal do Rio de Janeiro (IP-UFRJ) e bolsista da Coordenação de Aperfeiçoamento de Pessoal de Nível Superior

(CAPES).

Email: mvgama@hotmail.com Orcid: https://orcid.org/0000-0002-6827-4580

\footnotetext{
1 O conceito de trágico pode ser encontrado em Nietzsche (2001/1873) e na primeira edição de História da loucura de Foucault, especialmente em seu prefácio (1994/1961). A escolha do personagem de Heleno de Freitas sobressai não apenas pelo aspecto trágico, mas é uma homenagem ao próprio jogador e também a uma das
} 
historiadoras mais marcantes na análise do trabalho de Michel Foucault em território brasileiro: Heliana Conde. A homenagem não vem apenas do viés botafoguense da historiadora, mas pelo trabalho rigoroso com os conceitos foucaultianos. O livro de Heliana sobre as trajetórias de Foucault no Brasil (RODRIGUES, 2016) é uma referência para os interessados no tema.

2 Em 1929, Boring escreve o livro Uma História da Psicologia Experimental, que se torna uma referência do campo nas décadas por vir, especialmente no estabelecimento das primeiras comunidades de psicólogos ditos científicos.

3 Esta consulta foi realizada em 26 de maio de 2021. O termo Biopoder gera 226.000 resultados. Outros conceitos como "anatomopolítica" produzem cifras mais modestas como 36.200 resultados. Os demais conceitos não oferecem boa comparação, pois confundem-se com temas correntes.

4 Como veremos mais ao final deste artigo, Nascimento da Biopolítica como curso se apresenta mais como réquiem do conceito, em que este termo deixa de designar uma forma especial de condução da conduta e se torna uma mera referência a uma escala de fenômeno populacional.

5 As estratégias de segurança (não necessariamente as técnicas de segurança) voltam em um breve comentário na terceira aula de Nascimento da Biopolítica, entendidas como a contraparte das formas liberais de governo: "Em resumo, a todos estes imperativos - velar para que a mecânica dos interesses não gere perigos, já seja para os indivíduos, já seja para a coletividade - devem responder às estratégias de segurança que, em certo sentido, são o reverso e a condição mesma do liberalismo" (FOUCAULT, 2007 [1978-79]: 86).

$6 \quad$ No curso seguinte, Foucault (2007 [1978-1979]) destaca, especialmente na quarta aula, que a presença da liberdade como modo de governo implica sempre em um complexo sistema de pesos e contrapesos. A entrada em cena de uma nova tópica das relações de poder distintas da inicial, proposta em termos de soberania - disciplina biopolítica (técnicas de segurança), não exclui, nas formulações sequentes (poder pastoral - Estado de polícia governamentalidade liberal), o retorno de figuras antigas. Assim é que a própria disciplina retorna como termo regulador das formas liberais: "Liberdade econômica, liberalismo no sentido em que acabo de dizer e técnicas disciplinares: aqui também as duas coisas estão perfeitamente ligadas" (FOUCAULT, 2007 [1978-79]: 88). Isso vale especialmente para o panoptismo: “o panóptico é a forma mesmo do governo liberal” (FOUCAULT, 2007 [1978-79]: 89). 